\title{
Negara dan Kawasan Islam dalam Kontek Politik Global
}

\author{
Armyn Hasibuan \\ Fakultas Dakwah dan Ilmu Komunikasi IAIN Padangsidimpuan \\ (E-mail: armynhasibuan@gmail.com)
}

\begin{abstract}
Global complications characterize cross-country relations allowing trade, capital investment to go beyond the national economy, the existence of AFTA, the economic boundaries of a country are penetrated online, the spread of ideas, politics and other cultures will continue to develop and traditional lifestyles so far will be challenged by modernity and westernization and the nation. those who are easily influenced will be able to leave the local tradition even if it is considered good and inherited from the ancestors. Winning nations, of course, those who have a big role in various fields, say, the owners of capital to invest in other countries, buy assets of poor countries, and can turn to politics. Even though Islamic countries and regions are involved in global complications, even though there is no formal international standard for the size of an Islamic country or region, people see the existence of the majority of the people, still struggling with underdevelopment, more often become objects than subjects, be it economic, political, educational and natural resources. natural resources that have belonged to other nations even though they remain at home due to debt and trade.
\end{abstract}

\section{Keywords: Regional, Political and Global Countries.}

\begin{abstract}
Abstrak
Komplik global mewarnai hubungan lintas antar negara memungkinkan perdagangan, investasi modal melampaui ekonomi nasional, adanya AFTA batas batas ekonomi suatu negra tertembus dengan online, penyebaran ide, politik dan budaya lainnya akan terus berkembang dan gaya hidup tradisional selama ini akan ditantang modernitasi dan westernisasi serta bangsa yang mudah terpengaruh akan dapat meninggalkan tradisi lokal meskipun hal itu dipandang selama ini baik dan warisan nenek moyang. Bangsa pemenang tentunya mereka yang memiliki peran besar diberbagai bidang, katakan saja pemilik modal untuk menanam investasi di negara orang lain,membeli aset negara miskin,dan dapat beralih ke dunia politik. Tak terkecuali negara dan kawasan islam turut dalam komplik global, meskipun belum ada standar formal internasional ukuran negara atau kawasan yang islam, orang melihat eksistensi rakyatnya manyoritas, masih bergumul dengan keterbelakangan, lebih sering menjadi objek ketimbang subjek, baik ekonomi, politik, pendidikan dan sumber daya alam yang telah milik bangsa lain meskipun tetap berada di negeri sendiri akibat utang dan perdagangan.
\end{abstract}

Kata Kunci : Negara Kawasan, Politik dan Global. 


\section{A. Pendahuluan}

Politik global berbeda dengan politik internasional yang berupaya memahami budaya antar negara, bangsa di berbagai hal secara universal, sementara politik global adalah perebutan legitimasi dalam lingkup politik golobal yang memiliki empat sub kategori yaitu: Konflik global, Kebijakan luar negeri, Organisasi kebijakan global, dan Pemerintahan dunia ${ }^{1}$

Mufread Steger mengidentifikasi globalisasi sebagai eksistensi dan dinamika golabal pada lima dimensi yaitu dimensi ekonomi, politik, budaya, ekologi dan ideologi yang di dalamnya termasuk agama ${ }^{2}$, bahkan perbatasan ruang lingkup global terus berkembang dan bertambah di bidang teknologi, hakhak asasi manusia dengan seluk beluk demokrasi.

Pemetaan global versi siapapun, negara-negara Islam tetap menjadi salah satu ranah dan ruang lingkupnya yang tidak bisa tereliminir dan uzlah alias diisolasi dari pengaruh politik global yang terus mencuat utamanya pada tahun 2000 an dan pasca tragedi 11 seftember 2001, pemboman gedung World Trade Center (WTC) New York Amerika Serikat. Dengan kejadian tragedi 11 september 2001 itu sebenarnya memberi indikasi bahwa meskipun sebelumnya Amerika Serikat di pandang telah memenangkan peperangannya dengan Uni Soviet (perang dingin) namun Amerika Serikat tidak juga bisa mengkalaim dirinya sendiri sebagai super power satu-satunya.

Dari sisi ekonomi tahun 2008 Amerika, dalam keadaan krisis seolah momen itu mengantar, negara-negara maju lainya bersaing untuk memperebutkan dominasi dalam ekonomi politik golobal tanpa hegemoni yang jelas. Buruh industry domistik AS. mulai memandang globalisasi Freetrade sebagai ancaman bagi national interest AS. karena buruh Asia ini lebih murah dan membanjiri pasar AS sehingga mengancam industri-industri dan meningkatnya defisit perdangangan AS ditambah lagi semakin membengkaknya biaya mempertahankan

\footnotetext{
${ }^{1}$ http : I/id. M. Wikipedia. Org, David Held " Politik Global "' Di akses minggu 10-112019 pukul 06.10 wib.

${ }_{2}^{2}$ Mufread Steger, Globalization: A Very Short Introduction, (New York: University Press, 2009), h.13.
} 
posisi hegemoni dan polisi dunia. Saat itu bermunculan pula kekuatan ekonomi baru (emerging country) dan NIC seperti jepang, cina dan East asia lainnya. ${ }^{3}$

Negara-negara Islam atau negara yang penduduknya mayoritas beragama Islam juga turut berkompetisi di pentas dunia dewasa ini. Golobalisasi yang berasal dari kata global, "World Wide ; Embarcing The whole of group of items". 4 yang berarti mendunia, melengkapi seluruh kelompok materi. Secara istilah dapat di lihat dari budaya pendekatan pengertian, yaitu:

Pertama, globalisasi menggambarkan hubungan lintas- perbatasan antara negara-negara. Dengan arus pertumbuhan dan pertukaran internasional memungkinkan perdagangan,investasi modal bergerak melampaui ekonomi nasional dan internasional.

Kedua, globalisasi sebagai liberalisasi artinya kebebasan pasar menghilanhkan batas batas ekonomi dunia dengan adanya perjanjian AFTA dan terus bergeraknya Negara-negara maju memasuki Negara negara lain bahkan dapat melewati pasar lewat Online.

Ketiga, globalisasi sebagai universalisasi dimana penyebaran berbagai objek dan pengalaman kepada orang-orang diseluruh penjuru dunia lewat kemajuan IT dan media lainnya. ${ }^{5}$

Keempat, globalisasi sebagai westernisasi atau modernisasi dimana dipahamkan sebagai dinamisasi cara berpikir dan gaya hidup seperti dalam struktur sosial modernitas yang berbentuk kapitalis, nasionalis, industrialism, birokratisme tersebar di seluruh dunia, akan memberikan peluang dan tantangan. Bila umat muslim atau negara negara islam mampu menjadikannya ladang peluang tentu menjadilah nilai tambah meskipun biasanya menghancurkan budaya lokal dan prosesnya amat menentukan nasib peradaban lokal itu sendiri. Ia digaungkan suatu negara atau kelompok dan menggeneralisasi pola hidup yang menjadi krakter khas mereka menjadikannya menembus seluruh batas

\footnotetext{
${ }^{3}$ Rudi rusdiah, Diplomasii, Unilateralisme kompetisi Global (Jakarta- Bandung : Alumni. Com, 2011) h. 26.

${ }^{4}$ Hornby AS , Oxfrrd Advencer Learner Dictionery (Britaim, Oxpord University Press, 1974), h. 366.

${ }^{5}$ Ghasemi Hakem, Globalization and International Relations: Actors Move From Non Cooperative to cooverative Games (Iran : IKIU 2012), h.3.
} 
dunia $^{6}$ apalagi melihat makna dan praktek politik lebih menjurus menghalalkan semua cara demi memperkaya diri, kelompok dan memajukan negara dan bangsa.

\section{B. Pengertian dan Identifikasi}

1. Negara-Negara Islam

Adapun negara islam adalah negara yang setiap perilaku politiknya di dasarkan atas nilai atau ajaran agama Islam yang bersumber pada al-Qur'an dan hadis Nabi Muhammad SAW. ${ }^{7}$ Penegakan keadilan, toleransi dan hidupnya Syariah baik dalam penegakan hukum pidana dan perdata terimplementasi di seluruh strata masyarakatnya. Bukan hanya politiknya juga kepemimpinan dan kepemerintahannya berdasarkan kitab suci al Qur'an dan hadis Rasul Saw.

Gusdur (KH. Abdurrahman Wahid) mengatakan Negara Islam itu yang sebenarnya tidak ada, Islam sebagai jalan hidup (Syariah) tidak memiliki konsep yang jelas tentang negara, apalagi negara Islam karena Islam tidak memilki konsep bagaimana Negara harus dibuat dan di pertahankan. ${ }^{8}$ Demikian juga pemikiran Buya Hamka sebagaimana dikutip oleh Yasril Ihzah Mahendra berpendapat bahwa agama Islam tidak mengenal lembaga kenegaraan seperti selama ini di kenal oleh kaum muslimin. Lembaga kekhalifahan tidak ada sangkut pautnya dengan ajaran agama, kepemerintahan, fungsi-fungsi kenegaraan. Hanya saja tidak menolak eksistensinya tidak memerintahkan dan tidak pula melarang, semuanya terserah kepada kita untuk dipertemukan dengan akal sehat dengan pengalaman-pengalaman dan kaidah yang ada disekitar kita. ${ }^{9}$

Negara Islam yang berdasarkan kepada al-Qur'an, hadis rasul Saw. dan seluruh lingkupan syariatnya, ini barangkali belum ada, hanya di zaman rasul Saw. Yang beliau praktekkan di kota Madinah dengan berhasilnya beliau

\footnotetext{
${ }^{6}$ Jabiry Muhammad Abid, Qadhaya Fil Fikr al Muashir (Beirut: Markaz Dirasat al Wahdah al-Arabiyah, 2001), h. 137.

7 Depdikbud., Kamus Besar Bahasa Indonesia (Jakarta: Balai Pustaka, 1998), h. 685.

${ }^{8}$ https: //Islami. Co /Negara Islam adalah Konsepnya, Di akses Minggu tanggal 04-082020 Pukul 21.00 WIB.

${ }^{9}$ Yusril Ihzah Mahendr, Pemikiran Politik Budaya Hamka, Makalah di Presentasikan Pada Seminar: Youth Islamic Study Club al-Azhar, (Jakarta 13-14 nopember 1989), h. 6.
} 
meletakkan batu pertama bahwa dengan perundang-undangan yang diterima oleh semua komunitas al-Ansor dan al Muhajirin dengan mempersilahkan rasul sebagai pemimpin mereka, baik sebagai pemimpin agama dan Negara.

Konsep berdirinya suatu Negara di kala itu telah di capai oleh rasul Saw. karena selain mempunyai umat atau rakyat, juga wilayah tritorial, diakusi oleh bangsa lain yakni suku-suku bangsa Yahudi disekitarnya seperti Bani al-Nadhir, Quraizah, musthaliq dan al-Qoinuqaq serta hadisnya telah menjadi tatanan perundang-undangan yang di taati di seluruh strata masyarakat. Keadilan, jaminan hidup bagi non muslim (kafir zimmy) dengan pembinaan etika moral bermasyarakat dan berpemerintahan dilakukan dan diterapkan, seperti Rasul sering mendelegasikan kepemimpinan bagi sahabat baik pada saat saroyah (peperangan yang tidak di ikuti rasul), atau menyangkut hakim-hakim untuk daerah ekspansi. Tidak ada saling menjatuhkan,tenteram ada qisas hukum yang seimbang, hidup damai, aman dan terkendali dengan motto Sami'na Wa atha'na Ya Rasulahloh.

Apabila kepemimpinan Muhammad SAW, al-Qur'an dan hadis rasul Saw. yang menjadi standar barometer, maka menurut hemat penulis negara Islam itu tidak ada dewasa ini sekalipun Arab Saudi sebagai yang di pandang lebih islami, itu hanya sekedar anggapan, karena masih banyaknya terjadi pelanggaranpelanggaran, tingginya pelanggaran HAM seperti terbunuhnya Jamal Khashogi sebagai wartawan pokal Arab Saudi di Turkey belum lama tahun silam.

Kemudian, standar lain disebut suatu Negara sebagai Negara Islam bila konstitusi dan dasar negaranya didirikan dengan berdasarkan syariat islam sehingga di sebut Republik Of Islam, seperti negara Iran, Pakistan, Turky, Libia dan lain-lainnya. Ada pula yang melihat standarlisasinya berada pada karakteristiknya yaitu: mayoritas rakyatnya atau masyarakatnya muslim, dasar negara hakekatnya ajaran dan aturan Islam, hukum yang berlaku sebenarnya 
adalah hukum Islam meskipun namanya bercirikan kearifan lokal dan adanya Baitulmal (kekuatan ekonomi). ${ }^{10}$

Empat karakteristik terakhir harus include menjadi satu kesatuan, sehingga suatu negara meskipun rakyatnya mayorita muslim, tetapi dasar negaranya bukan Islam dan hukum perundang-undangannyapun tidak syariat Islam seperti Indonesia, maka tidaklah disebut negara Islam.

Negara Islam tidak ditemukan dalam al-Qur'an melainkan Lisanul Arab menunjukkan tidak adanya orang Arab mengunakan kata daulah dengan pengertian negara. Mereka hanya mengatakan kata daulah dengan makna Ugbah Fi al Mal wa al-Harb yakni perputaran harta kekayaan dan peperangan. Hanya saja Ibnu Khaldun dalam kitabnya "Muqaddimah" memakai kata daulah dengan arti negara.

\section{Politik Global}

Pada dekade terakhir dari abad ke 20, orang baru sadar bahwa pembangunan ekonomi dan industrialisasi dengan teknologinya adalah suatu kegiatan yang menyatu, bahkan Iptek menjadi ujung tombaknya pembangunan ekonomi, sementara iptek baru diperoleh ketika sumberdaya manusianya mapan ekonomi. Dari statemen itu memberi pemahaman ekonomi menduduki posisi penting dan menentukan. Di abad ini pula orang menyadari bahwa manusia tidak perlu takut di landa teknologi melalui industrialisasi, apabila suatu negara memiliki:

a. Strategi politik pengembangan teknologi dan ilmu pengetahuan

b. Starategi autonomi teknologi dan ilmu pengetahuan

c. Strategi pendidikan SDM untuk mampu mewujudkan a dan b. ${ }^{11}$

Untuk mewujudkan strategi ini diperlukan konsep keterkaitan, pengintegrasian dan kenyataan menyatunya rekayasa sosial dalam mengsingkronkan persepsi dari masing-masing inprastruktur sosial-politik-

\footnotetext{
${ }^{10}$ https://id. M. wiktionary. Org 'Negara Islam'” Di akses Selasa 03 Desember 2019 Pukul 08.45 WIB.

${ }^{11}$ Astrid S. susanto-sunario, Globalisasi dan Komunikasi (Jakarta:pustaka sunan harapan, 1995), h. 10-11
} 
ekonomi dan budaya, yang perlu saling menunjang dalam pengembangan ilmu dan teknologi melalui industrialisasi.

Hal pengintegrasian sosial politik, ekonomi dan budaya serta sumber daya manusia sering tertinggal dan terkesan berjalan sendiri sendiri di dunia Islam. Cobalah kita perhatikan negara mayoritas penduduknya muslim integritas sulit di wujudkan, pada hal bersatu itu lahirnya kasih sayang, kasih sayang akan membentuk ukhuwah yang lebih kental dan datangnya rahmat, sementara bercerai berai itu adalah azab kesengsaraan dan kehancuran.

Yang terjadi, perpecahan hanya disebabkan hal hal furu' bukan yang standar seperti masalah sunnah bukan fardu aini, perbuatan-perbuatan amoral terjadi di mana mana, tak berdaya seolah terbiarkan begitu saja. Banyak bersikap rakus, ingin berkuasa, loyal ke atasan lalu mencari pengaman, dilakukan dengan wajah yang lebih luhur demi raja dan pangeran, alasan kepentingan negara yang muncul secara dramatis dalam dilemma revolusioner. Dalam semua strata takterbantahkan secara diam-diam korupsi, kolusi dan nepotisme tetap beroperasi meskipun terus diburu. Para ahli melihat ini sebagai kekotoran pejabat intern suatu negara baik di negara-negara maju ${ }^{12}$ maupun lainnya tapi sering idealis terlenakan oleh rayuan dan pertemanan.

Tragedi kemanusiaan berbasis terorisme bersifat domistik regional, tetapi sebab musabbabnya setelah di telusuri secara bersama dan mendalam hal itu adalah dimensi politik global. Misalkan saja tragedi WTC di Amerika serikat 11 september 2001 tadi berbuntut pada pembumihangusan Irak, pembantaian dan pembunuhan secara keji di Palestina dengan kedok Isis. Tragedi kemanusiaan di Ukraina dan Somalia. Sebagai pemerhati Islam dan timur tengah menengarai bahwa motif gerakan radikalisme merupakan antitesa dari keserakahan politik, ekonomi, kekuasaan dan keangkuhan peradaban. ${ }^{13}$ Radikalisme Islam dengan aktivis sekularisme, pluralisme dan liberalisme agama sudah berlangsung cukup lama dan tidak ada habis-habisnya.

\footnotetext{
${ }^{12}$ Dennis F. Thompson, Etika Politik Pejabat Negara, Terj, Y. Sudarminta dari: Political Ethics and Public Office (Jakarta: Yayasan Obar Indonesia, 2002), hlm. 2.

${ }^{13}$ M. Sidi Ritaudin, Radikalisme Negara dan Kekuasaan Perspektif Politik Global (Jurnal Kalam, ISBN 389-414) 2014.
} 


\section{Diskriptif Negara Negara Islam Dalam Kontek Politik Global}

Pemahaman tentang skop politik global tetap perhelatan bagi para ilmuan dimana sebagian melihat sub subnya secara komprehensif yang mencakup ekonomi, politik, budaya, ekologi, ideology, teknologi, HAM, agama dan demokrasi. Di sisi lain melihatnya cukup empat substansi yaitu komplik global, kebijakan luar negeri, organisasi kebijakan global dan pemerintahan dunia.

Baik secara komprehensif maupun empat substansi dimaksud di atas bila dipandang pada negara negara muslim umumnya memiliki problema tersebut dengan berbeda jenis problema yang dihadapi. Tidak terpungkiri bahwa negaranegara muslim pada umumnya masih dikategorikan sebagai negara berkembang belum modern (kelompok G 20).

Kasuistik umat muslim di berbagai negara dalam menyikapi politik global masih lebih banyak sebagai objek daripada subjek, sebenarnya terlalu lama kesadaran global intern untuk dapat kembali membangun dunia dengan motiv rahmatan lilalamin itu, padahal magnum terbaik umat muslim pernah mewarnai peradaban dunia dan diakui Eropa mereka berutang budi kepada islam utamanya membangkitkan keilmuan dan semangat belajar lewat renaissance menuju kemuliaan peradaban. Hendaknya negara negara muslim mampu memperkokoh OKI dan berpartisipasi mengikuti negara negara maju memberi andil diberbagai bidang pembangunan kemanusiaan, sains, etika dan teknologi serta pertukaran pertukaran cendikiawan, mahasiswa dan sumberdaya manusia genius lainnya.

Memang disadari hakekat dari firman Allah dalam Q.S. al-Baqarah :120 ${ }^{14}$ mengingatkan bahwa Yahudi dan Nasrani tidak senang bilamana umat islam menjadi pelopor dan qudwah, oleh itu tak terkecuali dibidang politik global meskipun ada etika politik belum terrealisasi oleh actor actor penentu globalisasi.

Dilema Islam dilema demokrasi, artinya Islam di pandang kontradiktif dan tidak konsisten, karena di satu sisi menyarukan perdamaian dan anti kekerasan, tapi di sisi lain islam membenarkan kekerasan dalam doktrin jihad, hal ini yang

${ }^{14}$ Depag R.I., al-Quran dan Terjemahnya ( Semarang : Toha Putra,2o15 ),h.32 
selalu diskursus yang dilahirkan dalam pentas diskusi ilmiah, meskipun berbagai macam logika berfikir yang dikedepankan. Dalam sejarah dinasti-dinasti Islam tak jarang diungkapkan Islam itu di sebarkan dengan pedang dan hukuman lalu ada yang menganggap tidak bisa dipertemukan, penafsiran beragama sementara demokrasi bergerak terus secara bebas dan dinamis dalam sejarah evolusi manusia. $^{15}$

Berikut ini gambaran sebagian negara muslim dalam kontek politik global yang terhimpun dalam berbagai substansi meskipun belum terakomodasi dan termenej secara berurutan, antara lain :

\section{Arab Saudi}

Bagi Saudi Arabia, selain Amerika Serikat mitra utama dalam kerjasama ekonomi adalah Tiongkok dan Jepang yang secara geografis berada di kawasan Asia Timur yang relatif sama dengan Indonesia. Nilai investasi Saudi Arabia di Tiongkok sebesar US\$ 65 miliar atau setara dengan Rp 867 triliun jauh lebih besar daripada investasi di Indonesia yang hanya sebesar US\$ 7 milyar atau setara dengan Rp 89 triliun. Jika dilihat dari nilai investasinya, maka di mata Saudi Arabia posisi Indonesia tidak lebih utama daripada Malaysia ${ }^{16}$. Nilai investasi Saudi Arabia di Indonesia jauh lebih kecil daripada investasi Singapura di Indonesia yang pada tahun 2009 mencapai nilai US\$ 9,18 milyar atau sekitar Rp. 122 trilyun. Sebagai negara pengimpor minyak, ternyata impor minyak Saudi Arabia ke Indonesia sebesar 6,3 juta ton lebih sedikit daripada Malaysia yang mencapai 7 juta ton dan Singapura yang mencapai 15,98 juta ton pada tahun $2015^{17}$

Di sisi lain, Saudi Arabia dan Iran merupakan dua aktor utama yang menentukan ke arah mana pendulum yang menggambarkan kondisi keamanan global akan bergerak. Persaingan kedua negara menjadi determinan temperatur politik keamanan di kawasan Timur Tengah. Sebagai negara dengan jumlah penduduk beragama Islam di dunia dan dengan citra sebagai negara muslim

${ }^{15}$ Ibid., h.327

16 Data diakses dari http://www.theaustralian.com.au/news/world/indonesias-jokowidodo-laments-saudi-investment-of-only-88bn/news-story/5b632f61b14255bebb873aef94f050bb

17 Data dikutip dari Badan Pusat Statistik (BPS) 
moderat (setidaknya hingga beberapa tahun terakhir ini), Indonesia dapat menjadi penengah di antara kedua negara, atau memberi warna, menggeser arah pendulum ke arah yang lebih baik.

\section{Indonesia}

Dalam catatan sejarah, masalah hak-hak asasi manusia (HAM) banyak yang terjadi diantaranya tragedi Tanjung Periuk yang tergolong pelanggaran HAM berat. Sebelum massa umat Islam dalam berunjuk rasa atas oknum ceroboh masuk musholla dengan tidak mencopot sepatu menyiram pengumuman pengajian di papan musholla dengan air comberan yang membuat beberapa orang muslim marah dan saat itu ada mobil yang terbakar. Dengan kejadian yang demikian 4 orang di tangkap dan diintrogasi serta diproses dibawa ke markas. Atas perlakuan inilah umat Islam tidak terima mereka unjuk rasa berjalan berbaris ke Kodim agar ke empat temannya di lepaskan. Di saat ini (1984) umat Islam yang unjuk rasa dengan tembakan bertubu-tubi, mayat bergelimpangan ratusan umat Islam di terjang peluru sementara yang lain ada pula yang mengalami luka-luka dan cacat seumur hidup. ${ }^{18}$

Hal itu perlu penelusuran apakah ada pengaruh politik luar dengan mengintimidasi orang orang tertentu di Indonesia, atau pikiran radikalisme di susupkan kepada anak bangsa atau orang kantoran atau militer? Demikian juga pasca tahun 2000an tampaknya umat islam Indonesia tetap menjadi kontradiktip dengan kehendak pemegang kekuasaan.

Sebetulnya tidak perlu ada dilema atau dikotomi dalam hal orientasi politik luar negeri Indonesia. Sebagai negara yang secara geografis berada di kawasan Asia Tenggara sangat logis jika Indonesia menjadikan ASEAN sebagai salah satu fokus utamanya, demikian pula dengan Amerika Serikat dan Tiongkok, kedua negara tersebut saat ini adalah aktor terpenting yang mendisain arah politik dan ekonomi global. Tetapi mengabaikan kawasan Timur Tengah juga bukan pilihan yang tepat. Selain secara kultural memiliki keterkaitan yang erat, kawasan Timur

${ }^{18}$ Depaq. R. I., Jejak-jejak Islam Politik, Sinopsias Sejumlah Studi Islam Indonesia (Jakarta: Ditpertais, 2004). h.29. 
Tengah merupakan episentrum ekonomi-politik global, tidak heran jika negaranegara adidaya seperti Amerika Serikat, Rusia dan Tiongkok mengerahkan perhatian utamanya di sana.

Arti penting kawasan Timur Tengah bagi dunia adalah selain karena kawasan ini menjadi sumber energi fosil bagi banyak negara juga dalam dimensi keamanan global kawasan ini menjadi penentu arah pendulum kondisi keamanan global. Beberapa perang besar yang terjadi baik sejak masa Perang Dunia I dan II, kemudian masa Perang Dingin maupun pasca Perang Dingin terjadi di kawasan ini. Terlebih lagi kini perang asimetrik yang melibatkan aktor-aktor nonnegara seperti kelompok-kelompok teroris transnasional berasal dari kawasan ini.

\section{Suriah}

Meskipun telah berlangsung selama empat tahun, hingga saat ini, konflik Suriah belum tampak akan berakhir. Sejak Maret 2011 konflik ini telah menelan korban yang tidak sedikit, ribuan pengungsi, dan ribuan anak menjadi yatim akibat kehilangan orangtua mereka. Ribuan rumah, infrastruktur dan sarana publik hancur. Tulisan ini berupaya memahami akar persoalan yang menjadi penyebab konflik Suriah, siapa aktor kunci yang terlibat dalam konflik, dan dampak konflik itu bagi Suriah dan dunia internasional.

Data-data tentang konflik Suriah dikumpulkan dari buku, jurnal, dan web. Data-data tersebut kemudian dikategorisasi, disistematisasi dan dianalisis sesuai dengan tujuan penulisan. Tulisan ini menyimpulkan bahwa sumber masalah atau penyebab lahirnya konflik Suriah bukanlah perbedaan mazhab keagamaan melainkan kepentingan politik dan ekonomi dari oposisi penentang Assad dan negara-negara pendukung oposisi, ada tiga aktor yang berperan dan terlibat dalam konflik, Presiden Bashar al-Assad dan para pendukungnya, oposisi Suriah, dan kelompok Jihadis.

Dampak konflik bagi Suriah jatuhnya korban jiwa dan pengungsi. Sejak meletusnya konflik pada Maret 2011 sampai dengan April 2013 jumlah korban meninggal sebanyak 150.000 jiwa. Sementara warga yang mengungsi sebanyak juta orang, 3/4 di antara pengungsi itu adalah anak-anak dan perempuan Sekitar 4 
juta warga Suriah yang kehilangan tempat tinggal dan tetap bertahan di Suriah sampai sekarang.

Bagi dunia internasional, konflik Suriah berdampak dalam penanganan pengungsi. Ada pandangan yang menyatakan bahwa perang yang saat ini terjadi Suriah adalah perang antara mazhab Syi'ah yang diwakili oleh Bashar al-Assad dan para penentangnya yang bermazhab Sunni. Pandangan ini dibangun atas fakta yang terjadi di Suriah: ada dua kekuatan besar yang sedang bertarung, yakni Arab Saudi yang bermazhab Sunni dan Iran bermazhab Syi'ah. ${ }^{19}$ Fakta lainnya adalah bahwa pemerintahan Assad didukung oleh Iran dan gerakan Hizbullah, Iran merupakan negara yang bermazhab Syi'ah dan Hizbollah adalah gerakan berhaluan Syi'ah yang bermarkas di Lebanon. Sebaliknya para penentang Assad mendapat dukungan negara-negara yang bermazhab Sunni seperti Arab Saudi, Quwait, dan Afganistan.

Sumber konflik, Pertama, masalah sosial, ekonomi dan politik di dalam negeri yang dihadapi oleh Suriah. Masalah-masalah itu antara lain berupa tingginya jumlah pengangguran, tingginya inflasi, terbatasnya kesempatan untuk mobilitas sosial, pembatasan kebebasan politik, dan aparat keamanan yang represif. Kedua, tuntutan sebagian penduduk Suriah agar dilakukan reformasi dan penggatian rezim Bashar al-Assad. Sejak tahun 1963, pemerintahan Suriah didominasi oleh Partai Baath, kemudian keluarga al-Assad, yakni Hafidz al-Assad yang memerintah sejak tahun 1970 hingga kematiannya di tahun 2000, dan digantikan oleh putranya, yakni Bashar al-Assad dan memerintah sejak tahun 2000 sampai dengan sekarang.

Selama empat puluh tahun di bawah pemerintahan klan Assad (Hafez alAssad dan anaknya Bashar al-Assad) pembangunan sosial dan ekonomi Suriah masih jauh dari memuaskan. Suriah tergolong dalam negara berkembang

${ }^{19}$ Anna Sunik dari Institut GIGA di Hamberg menyatakan bahwa sejak revolusi Islam di Iran 1979 Saudi memang ingin membendung pengaruh Iran, Lihat www.dw.de, "Kepentingan Arab Saudi dalam Perang Suriah," hlm. 28 
berpendapatan menengah. Perekonomiannya ditopang terutama oleh minyak dan pertanian, sejak 2004 Suriah dikenai sanksi ekonomi oleh AS yang melarang atau membatasi ekspor-impor ke Suriah. ${ }^{20}$

\section{Tunisia}

Peristiwa bakar diri yang dilakukan oleh seorang pedagang, kemudian memicu gelombang protes rakyat Tunisia kepada penguasa tiran di negeri itu. Apa yang terjadi di Tunisia kemudian menjalar ke negara-negara Arab lainnya. Negara di kawasan Afrika Utara yang berbatasan langsung dengan Tunisia yaitu Libya juga terjadi pergolakan menuntut pergantian rezim Kadlafi. Berbeda dengan Tunisia yang tidak sampai terjadi perang saudara, di Libya perang saudara pecah. Bahkan kekuatan eksternal yaitu NATO ikut terlibat langsung dalam konflik domestik ini dengan mendukung kelompok oposisi. Sampai pada akhirnya regime Kadlafi tumbang ditandai dengan tewasnya yang bersangkutan dalam sebuah penghadangan yang dilakukan oleh kelompok oposisi.

Selain itu, apa yang terjadi di Timur Tengah adalah realitas politik internasional yang bersifat anarchy ketika institusi global seperti Liga Arab, Organisasi Konferensi Islam, dan Perserikatan Bangsa-Bangsa yang diharapkan bisa mencegah kekisruhan politik yang memakan korban jiwa dalam jumlah besar seperti yang terjadi di Syria tidak mampu menjalankan perannya dengan baik. Global governance yang diharapkan mampu menangani hal-hal teknis, kelembagaan, aturan, norma, kesepakatan-kesepakatan legal untuk mengatur hubungan antar negara dan juga untuk memfasilitasi dinamika hubungan antar negara yang mengalami konflik sebagai akibat dari kekisruhan domestik ternyata belum maksimal mengambil perannya.

\section{Palestina}

Salah satu konflik internasional yang berkepanjangan dan entah sampai kapan akan berakhir adalah konflik arab-palestina-israel. Berkepanjangannya konflik ini disamping disebabkan karena dukungan yang membabi-buta oleh

\footnotetext{
${ }^{20}$ Dina Y. Sulaeman, Praha Suriah: Membongkar Persekongkolan Multinasional (Depok: IMaN, 2013) hlm. 24
} 
Amerika Serikat terhadap isrel, tetapi juga karena struktur PBB khusunya struktur DK-PBB yang sejak awal berdirinya memang tidak demokratis dan tidak representatif. Untuk itu agar konflik ini dapat segera berakhir dan mimpi bangsa Palestina untuk memiliki sebuah negara merdeka dan berdaulat penuh, mutlak dilakukannya restrukturisasi terhadap DK-PBB agar lebih demokratis dan representative. Dalam rangka inilah peran Organisasi Islam (OKI) sangat penting dan strategis untuk membangun solidaritas dan soliditas negara-negara islam dan berpenduduk mayoritas muslim guna mendesak PBB untuk melakukan restrukturisasi diri menuju PBB yang lebih demoratis.

Ketergantungan antar bangsa dan negara dewasa ini bukan saja dibidang ekonomi melainkan menyangkut disegala bidang kehidupan manusia seperti bidang hubungan politik, militer, sains, pendidikan, teknologi apalagi obat obatan di masa covid-19 yang semua negara membutuhkan paksin yang dapat mengatasi. Kenyataan ini nampak jelas bahwa tidak ada satu negarapun yang tidak memerlukan negara atau bangsa lain.

\section{Iran}

Negara iran memiliki proses pengarahan sistem politik dari monarki ke sistem republik tanpa sedikit pun meneteskan darah rakyat, artinya ide revolusi Islam Iran bergerak merambah jantung masyarakat segera setelah Fatwa Khomaini tahun 1978. Penggalangan kekuatan revolusi untuk meruntuhkan pemerintahan monarci Shah Reza dan menggantinya dengan pemerintahan islam. Pada 4 seftember 1970. Revolusi ini di latarbelakangi antara lain:

a. Terbentuknya partai sosialisasi Restakhiz tahun 1974

b. Pergantian kalender Hijrah dengan kalender kerajaan

c. Syahidnya Ayatallah Rubullah Khoucini

d. Memberi sugesti oihak luar negeri yang kontra-idiologis dengan Amerika Serikat sebagai sekutu shah Iran.

e. Menjauhi bekerjasama dengan partai-partai liberal

f. Pemanfaatan isu-isu keislaman untuk, memperoleh legitimasi sekaligus membangkitkan rasa anti Amerika di kalangan masyarakat muslim Iran. ${ }^{21}$

Inilah suatu bukti bahwa umat islam jangan hanya objek tetapi dapat sebagai subjek yang mendidik dan membawa umat untuk lebih sadar akan tantangan dan

21 Husaini M. Daud dan Nordan, Kebangkitan Revolusi Iran, Makalah Prosidung SNYuBE 2013, Banda Aceh. Di akses Selasa, 03 Desember 2019. 
peluang globalisasi beserta pengaruhnya, kekuatan tim dalam menghadapi berbagai problematika baik di masa pra globalisasi dan juga pasca globalisasi di negara masing-masing

\section{ETIKA GLOBAL}

Sesuai yang namanya etika adalah sistem nilai baik buruk, pantas atau tidak pantasnya dilakukan sesuatu yang acuan standarnya adalah akal sehat. Tanpa terkecuali orang waras baik di Asia, Afrika, Eropa, Amerika ,Australia dan lainnya akal sehat itu selalu mampu mengkaji keseimbangan dan kemaslahatan bagi kemanuasiaan. Oleh karena itu dalam tataran konsep etika politik global seharusnya merumuskan ketertiban dunia, mempokuskan perhatian pada struktur global dan proses pembuatan undang undang, pemecahan masalah global untuk kepentingan bersama ${ }^{22}$ pemeliharaan keamanan, keseimbangan ekologi, dan ketertiban dalam rakitan sistem dunia bersama.

Kemudian dengan globalisasi hubungan yang saling bergantung antara negara-bangsa, pelaku transnasional yang terintegrasi secara global, tidak mungkin lagi diselesaikan oleh masing masing negara nasional secara sendirian melainkan bersama sama sebagai komunitas warga dunia, tentu hubungan besar itu membutuhkan etika yang humanis.

Dalam menyikapi terwujudnya realisasi etika global itu dibutuhkan global govermance yang dapat membentuk secara formal hukum berbentuk informal dalam rupa temporal, misalnya kajian isu lingkungan hidup, perambahan hutan sebagai paru paru dunia, AIDS dan lain lainnya. Akan tetapi harapan dan rumusan itu semua secara realitas lebih mengarah pada pembelaan diri dan negara masing masing atau ketidak adilan sesuai tuntutan kemanusiaan.

Dalam kehidupan ekonomi misalnya IMF dan Bank dunia belum mampu mewujudkan kesetaraan membantu negara negara yang kena krisis moneter

22 Retna Dwi Estuningtyas, Dampak Globalisasi pada Politik,Ekonomi,Cara Berfikirdan ideology Serta Tantangan dakwah (Jurnal), Univ.Ibnu chaldun 2018. 
dengan mengambil alih komando manajemen perekonomian negara penerima bantuan bahkan kebijakan IMF memperburuk krisis di Indonesia dan Thailand. ${ }^{23}$

Demikian jugalah kepada negara negara muslim lainnya dapat diketahui lewat kecanggihan media dewasa ini seperti lewat TV ,medsos dan alat komunikasi lainnya, betapa ketidak seriusan negara adidaya dan pemegang hak peto di PBB dalam mengatasi dan menyelesaikan berbagai komplik antar negara seperti Israel dengan Pelistina yang sudah puluhan tahun tak kunjung aman dan bersahabat' bahkan memperhatikan selogan medsos muncul dibenak kita benarkah peta Palestina akan dihapus? Oleh siapa? Dan apa kata dunia? Apa pula tuntutan nilai etik dari etika politik global? Atau hanya konsep membangun dunia baru yang kita seluruhnya sebagai warganya aman dan berkemajuan?Apakah kembali kepada hukum alam yang kuat tetap tindas yang lemah ?Manusia serakah bila tak diiringi etika dan akhlak? Semuanya terpulang kepada manusia itu sendiri.

\section{E. Kesimpulan}

Globalisasi ditandai oleh pola hubungan yang saling terkait satu dengan yang lain tanpa dibatasi oleh batas batas kewilayahan. Hubungan antar negara atau antar kawasan terjadi sedemikian rupa sehingga ada ketergantungan yang dapat dikatakan sulit dipisahkan.

Negara negara islam dalam kontek politik global masih cenderung sebagai objek daripada subjek, dimana arus pertumbuhan ekonomi dan pengelolaan sumberdaya alam yang mereka miliki masih tergantung pada SDM negara lain bahkan sering menjadi komoditi bagi negara negara maju dalam bidang ekonomi, politik, teknologi, HAM dan demokrasi lainnya. sehingga memungkinkan perdagangan, investasi modal bergerak melampaui ekonomi nasional dan internasional.

Globalisasi sebagai westernisasi atau modernisasi dimana dipahamkan sebagai dinamisasi cara berpikir dan gaya hidup seperti dalam struktur sosial

23 Stiglitz Joseph E., Kegagalan Globalisasi dan Lembaga Lembaga Keuangan Internasiopnal,Terj. A.Luqman ( Jakarta: Ina Publikatana,2012),h.24 
modernitas yang berbentuk kapitalis, nasionalis, industrialism, birokratisme tersebar di seluruh dunia. Biasanya menghancurkan budaya lokal dan prosesnya amat menentukan nasib peradaban lokal itu sendiri. Etika politik akankah dapat menjadi sistem nilai yang mengatur dan menjadi krakteristik actor actor globalis menjadi lebih humanis dan saling membantu.

Bumi sebagai pentas hidupnya milliard umat manusia tidak terkecuali harus mendapat etika gelobal, perhatian, pemeliharaan dan kerjasama dunia agar polusi udara,perambahan hutan yang telah menjadi ekosistem nasional, regional antar negara. Kerusakan lingkungan hidup, masyarakat secara gelobal akan berdampak negative pula secara gelobal, tidak obahnya bagaikan virus corona akan merebak menjadi pandemi lagi bilamana tidak secara keseluruhan melibatkan diri bersinergi dan bertindak dengan cara bagaimanapun untuk menghindarinya. 


\section{DAFTAR PUSTAKA}

Astrid S. susanto-sunario, Globalisasi dan Komunikasi, Jakarta: Pustaka Sunan Harapan, 1995.

Dennis F. Thompson, Etika Politik Pejabat Negara, Terj, Y. Sudarminta dari: Political Ethics and Public Office, Jakarta: Yayasan Obar Indonesia, 2002.

Depag R.I., al-Quran dan Terjemahnya, Semarang : Toha Putra, 2015.

Depaq. R. I., Jejak-jejak Islam Politik, Sinopsias Sejumlah Studi Islam Indonesia, Jakarta: Ditpertais, 2004.

Depdikbud., Kamus Besar Bahasa Indonesia, Jakarta: Balai Pustaka, 1998

Dina Y. Sulaeman, Praha Suriah: Membongkar Persekongkolan Multinasional, Depok: IMaN, 2013

Ghasemi Hakem, Globalization and International Relations: Actors Move From Non Cooperative to cooverative Games, Iran : IKIU 2012.

Hornby AS , Oxfrrd Advencer Learner Dictionery Britaim, Oxpord University Press, 1974

Husaini M. Daud dan Nordan, Kebangkitan Revolusi Iran, Makalah Prosidung SNYuBE 2013, Banda Aceh. Di akses Selasa, 03 Desember 2019.

Jabiry Muhammad Abid, Qadhaya Fil Fikr al Muashir, Beirut: Markaz Dirasat al Wahdah al-Arabiyah, 2001.

Mufread Steger, Globalization: A Very Short Introduction, New York: University Press, 2009.

M. Sidi Ritaudin, Radikalisme Negara dan Kekuasaan Perspektif Politik Global, Jurnal Kalam, ISBN 389-414, 2014.

Retna Dwi Estuningtyas, Dampak Globalisasi pada Politik, Ekonomi, Cara Berfikirdan ideology Serta Tantangan dakwah (Jurnal), Univ.Ibnu chaldun 2018.

Rudi rusdiah, Diplomasii, Unilateralisme kompetisi Global, Jakarta- Bandung : Alumni. Com , 2011.

Stiglitz Joseph E., Kegagalan Globalisasi dan Lembaga Lembaga Keuangan Internasiopnal, Terj. A.Luqman, Jakarta: Ina Publikatana, 2012.

Yusril Ihzah Mahendr, Pemikiran Politik Budaya Hamka, Makalah di Presentasikan Pada Seminar: Youth Islamic Study Club al-Azhar, (Jakarta 13-14 nopember 1989).

Yusuf Anwar, Pasar Modal Sebagai Sasaran Pembiayaan dan Investasi (Bandung: Pt, Alumni, 2010)

Yusuf Qardhawi, Ummatuna Baina Qarnain (Beirut : Daar al- Syuruq, 1421)

http : I/id. M. Wikipedia. Org, David Held " Politik Global " Di akses minggu 10-11-2019 pukul 06.10 wib.

https: //Islami. Co /Negara Islam adalah Konsepnya, Di akses Minggu tanggal 112-2019 Pukul 21.00 WIB.

https://id. M. wiktionary. Org 'Negara Islam', Di akses Selasa 03 Desember 2019 Pukul 08.45 WIB.

http:/www.theaustralian.com.au/news/world/indonesias-joko-widodo-lamentssaudi-investment-of-only, Di akses Selasa 03 Desember 2019 Pukul 18.45 WIB. 